\title{
Consequences of Atomic Oxygen Interaction With Silicone and Silicone Contamination on Surfaces in Low Earth Orbit
}

Bruce A. Banks, Kim K. de Groh, and Sharon K. Rutledge

Glenn Research Center, Cleveland, Ohio

Christy A. Haytas

Cleveland State University, Cleveland, Ohio

Prepared for the 44th Annual Meeting sponsored by the International Society for Optical Engineering Denver, Colorado, July 21, 1999

National Aeronautics and Space Administration

Glenn Research Center 
This report is a preprint of a paper intended for presentation at a conference. Because of changes that may be made before formal publication, this preprint is made available with the understanding that it will not be cited or reproduced without the permission of the author.

Available from

NASA Center for Aerospace Information 7121 Standard Drive

Hanover, MD 21076

Price Code: A03
National Technical Information Service 5285 Port Royal Road Springfield, VA 22100

Price Code: A03 


\title{
CONSEQUENCES OF ATOMIC OXYGEN INTERACTION WITH SILICONE AND SILICONE CONTAMINATION ON SURFACES IN LOW EARTH ORBIT
}

\author{
Bruce A. Banks, Kim K. de Groh, Sharon K. Rutledge \\ National Aeronautics and Space Administration \\ Glenn Research Center \\ Cleveland, Ohio 44135 \\ Christy A. Haytas \\ Cleveland State University \\ Cleveland, Ohio 44115
}

\begin{abstract}
The exposure of silicones to atomic oxygen in low Earth orbit causes oxidation of the surface, resulting in conversion of silicone to silica. This chemical conversion increases the elastic modulus of the surface and initiates the development of a tensile strain. Ultimately, with sufficient exposure, tensile strain leads to cracking of the surface enabling the underlying unexposed silicone to be converted to silica resulting in additional depth and extent of cracking. The use of silicone coatings for the protection of materials from atomic oxygen attack is limited because of the eventual exposure of underlying unprotected polymeric material due to deep tensile stress cracking of the oxidized silicone.

The use of moderate to high volatility silicones in low Earth orbit has resulted in a silicone contamination arrival at surfaces which are simultaneously being bombarded with atomic oxygen, thus leading to conversion of the silicone contaminant to silica. As a result of these processes, a gradual accumulation of contamination occurs leading to deposits which at times have been up to several microns thick (as in the case of a Mir solar array after 10 years in space). The contamination species typically consist of silicon, oxygen and carbon, which in the synergistic environment of atomic oxygen and UV radiation leads to increased solar absorptance and reduced solar transmittance. A comparison of the results of atomic oxygen interaction with silicones and silicone contamination will be presented based on the LDEF, EOIM-III, Offeq-3 spacecraft and Mir solar array in-space results. The design of a contamination pin-hole camera space experiment which uses atomic oxygen to produce an image of the sources of silicone contamination will also be presented.
\end{abstract}

\section{INTRODUCTION}

Silicones have been widely used on spacecraft over the years for a wide variety of functions including potting compounds, adhesives, seals, gaskets, hydrophobic surfaces and atomic oxygen protective coatings. Since the advent of Space Shuttle-launched low Earth orbital (LEO) spacecraft, the effects of atomic oxygen interactions with silicone and silicone contaminants have been a cause for concern where elastomeric properties, solar absorptance, optical properties and surface cleanliness are important. The objective of this paper is to review results of spacecraft experiences where atomic oxygen has interacted with silicones and silicone contamination in order to enable LEO spacecraft designers to be aware of potential silicone material interactions as well as contamination issues. Current silicone contamination issues being investigated which may provide further insight into the causes and effects of atomic oxygen interactions with silicone contaminants will be presented.

Correspondence: Bruce A. Banks. Tel: (216) 433-2308; Fax: (216) 433-2221: E-mail: Bruce.A.Banks (a)grc.nasa.gov. 


\section{METHODS AND MATERIALS}

Data is drawn from the experiences of four spacecraft which have flown in low Earth orbit, a ground laboratory contamination test, and a planned in-space experiment.

\subsection{Long Duration Exposure Facility (LDEF)}

The LDEF spacecraft was launched by the Space Shuttle in 1984 into an orbit $476 \mathrm{~km}$ above the Earth and was in LEO for 5.8 years. The cylindrical shape of the LDEF spacecraft and axis of its moments of inertia enabled it to be gravity gradient stabilized with a fixed orientation with respect to the atomic oxygen ram direction (ref. 1). This spacecraft contained a wide variety of silicones ranging from potting compounds, adhesives, and atomic oxygen protective coatings to minor ingredients in thermal control paints. The spacecraft was exposed to an atomic oxygen fluence of $9.09 \times 10^{21}$ atoms $/ \mathrm{cm}^{2}$ on the ram facing surface which provided valuable high fluence atomic oxygen data on hundreds of materials including silicones and silicone contamination (ref. 2). Results of atomic oxygen interaction with silicone adhesives, silicone coated acrylic hicycle retroreflectors and silicone contamination are presented.

\subsection{Evaluation of Oxygen Interactions With Materials III (EOIM-III)}

The EOIM-III flight experiment was a LEO Shuttle in-bay experiment flown from July 31 to August 7, 1992. This experiment exposed a variety of materials to an atomic oxygen fluence of $2.3 \times 10^{20}$ atoms $/ \mathrm{cm}^{2}$ (ref. 3). This space experiment contained silicones which were directly exposed to atomic oxygen as well as sources of silicones whose contaminants were allowed to deposit on surfaces which were simultaneously exposed to atomic oxygen.

\subsection{Mir Solar Array Return Experiment}

In 1997, a solar array segment from the non-articulating photovoltaic array on the Russian Mir core module was removed and returned to Earth after LEO exposure of more than 10 years (ref. 4). One of the eight foldable panels from this array was inspected and microscopically examined by a collaborative team of U.S. and Russian scientists. Silicones contained in fabrication of this array were sources of silicone contamination on the array and handrail surfaces which were also exposed to atomic oxygen.

\subsection{Offeq Satellite Sun Sensors}

An Israeli Offeq- 3 spacecraft, launched in 1996 into a $369 \times 730 \mathrm{~km}$ orbit (ref. 5), contained two sun sensors exposed to silicone contamination and hydrocarbon contamination in an environment where atomic oxygen attack occurred (ref. 6). The consequences of the in-space exposure will be presented along with plans to simulate the Offeq exposure to understand the synergistic effects of silicone contamination, hydrocarbon contamination and atomic oxygen interactions in a ground-laboratory atomic oxygen beam facility at the NASA Glenn Research Center.

\subsection{Polymers Erosion And Contamination Experiment (PEACE)}

A planned Get-Away Special (GAS) Can experiment containing silicone contamination cameras will be presented which is intended to provide images of silicone contamination sources by making use of environmental atomic oxygen to fix the contaminant. 


\section{RESULTS AND DISCUSSION}

\subsection{Atomic Oxygen Interaction with Silicones}

LEO atomic oxygen bombardment of silicones results in the oxidation of the methyl groups and a gradual conversion of the silicone to silica (ref. 7). The consequences of the surface oxidation is a gradual increase in the surface elastic modulus accompanied by the development of contracted surface tensile stress ultimately leading to cracks of oxidized silicone. Figure 1 shows an optical photograph of a sample of DC-93-500 silicone which was exposed during the EOIM-III mission to a fluence of $2.3 \times 10^{20}$ atoms $/ \mathrm{cm}^{2}$. As can be seen from figure 1 , tensile cracks have formed on the surface of this sample. Atomic force microscopy indentation analysis indicates that the indent force per indent distance increases with atomic oxygen fluence and gradually approaches that of fused silica at extremely high atomic oxygen fluences (ref. 8). Similarly the elastic modulus changes from a low modulus of silicone towards a high modulus of fused silica with increasing atomic oxygen fluence.

Silicones exposed to a high atomic oxygen fluence result in a deeper conversion of the silicone to silica with the concomitant surface shrinkage resulting in secondary branch cracks as shown in figure 2 . The cracks are much deeper and wider as a result of the silicone being oxidized to a higher fluence $\left(4.92 \times 10^{21}\right.$ atoms $\left./ \mathrm{cm}^{2}\right)$ than for the sample shown in figure 1. Silicones have been used for atomic oxygen protection because they form a silica protective coating. However, shrinkage of the surface of the silicones as a result of their conversion to silica can cause the coatings to become nonprotective in the crack sites, thus allowing underlying material to be exposed to atomic oxygen attack. This situation occurred with respect to silicone coated acrylic retroreflectors which were mounted on the LDEF spacecraft for retrieval purposes. Figure 3 is a scanning electron microscope photograph of a typical LDEF retroreflector after exposure to a sufficient atomic oxygen fluence to oxidize and crack the full thickness silicone protective coating. The formation of surface cracks can be reduced or even eliminated if the initial silicone surface is constructed with a highly roughened surface consisting of microscopic peaks and valleys (ref. 9).

\subsection{Atomic Oxygen Interaction with Silicone Contamination}

Silicones used in space have contained varying amounts of volatile species. The contamination caused by silicone volatiles in LEO can become a significant problem with time because silicone deposits may be converted to silica through atomic oxygen attack thus fixing the contaminant to the surface and preventing its re-evaporation. Silicone volatiles from the Passive Solar Array Materials Experiment on LDEF caused dark deposits to develop on surfaces which were exposed to the silicone volatiles and atomic oxygen attack. Figure 4 shows a photograph of white silicone rubber samples on the LDEF experiment which deposited contaminants to the right of the sample but only in areas where atomic oxygen bombardment could occur. As can be seen from figure 4, just adjacent and to the right of the sample there is a rather clear area where atomic oxygen was shadowed from bombardment of the depositing silicone contaminants, thus allowing the contaminants to revolatilize. Farther to the right of the sample, atomic oxygen converted the silicone to silica, thus trapping it in place and allowing it to darken under ultraviolet radiation exposure (ref. 1).

Silicone volatile species were present from numerous sources on the LDEF spacecraft resulting in the deposition of silicones and their conversion to silica. Some silicones were probably deposited from return flux processes. This occurs when the silicone species emanating outward from the spacecraft are reflected back as a result of collisions with environmental gaseous species. When such volatile silicone species land on surfaces which are already metal oxides, then there is typically sufficient time for the atomic oxygen to convert a portion of the species to silica. thus fixing them to the surface and allowing their gradual increase in thickness with time and gradual darkening in UV radiation. Figure 5 is a photograph of an LDEF experiment tray showing the surface of the tray which is interior to the LDEF spacecraft. The corner of the tray allowed atomic oxygen to enter from the upper left and impinge upon the right face of the edge of the tray. The silicone contamination being transported interior to the LDEF spacecraft came in contact with all portions of the tray surface. In those areas where simultaneous atomic oxygen bombardment occurred, the silicone was converted to silica and gradual darkening due to UV radiation occurred. As can be seen from figure 5, the clear shadows indicate the arrival direction of atomic oxygen. 
If the silicone contaminants are arriving on a hydrocarbon polymer surface, which is being exposed simultaneously to atomic oxygen, the silicone can often be carried away with the oxidation products of the hydrocarbon polymer. This is especially true if the fluxes of the silicone contaminants are sufficiently low. However, cases have been noted on the EOIM-III Space Station Freedom Array Materials Erosion flight experiment where silicones were arriving with sufficiently high flux as to form a protective silica coating over the underlying polyimide Kapton, thus preventing its atomic oxygen erosion in the areas of high silicone contaminant arrival. In contrast with surface cracking associated with atomic oxygen interactions with bulk silicones, atomic oxygen exposure of depositing silicone contaminants seems to produce a rather unstressed crack-free coating. However, the surface roughness of this coating gradually increases with contaminant thickness.

An abundance of silicone contaminants have been found deposited on surfaces associated with the solar array retrieved from Mir. A photograph of the back surface of the retrieved Mir solar array is shown in figure 6 . The Mir solar array panel 8 had flexible hand holds which were wrapped with a woven polymer fabric tape. This fabric received silicone contaminant flux, from silicones used in the laminate construction of the cover glass, glass fabric, solar cell, another glass fabric layer, and an optical solar reflector. This laminate construction contained a significant amount of silicone which appeared to evolve at suture penetrations around the perimeter of each cell at the sites where the cells were sewn to a structural mesh backing. The silicones contaminating the fabric tape on the hand rail were oxidized by atomic oxygen to produce a silica contaminant of $\sim 0.6 \mu \mathrm{m}$ thickness (ref. 10). Figure 7 is a scanning electron microscope photograph of the oxidized silicone contaminant spalling from the fibers of the fabric tape on the hand holds of the Mir solar array.

Silicone contamination on the back surface of the solar array optical solar reflectors retrieved from Mir are shown in figure 8 . As can be seen from figure 8 , the silica contaminant is highly visible in contrast to the area which was cleaned by tape peeling (where the contaminant readily separated from the surface of the optical solar reflector). It also can be seen that the contaminant is of varying thickness across the back of the solar cell because the sources of the silicone deposition occurred at discrete locations around the perimeter of the cell allowing the silicone species to deposit and be oxidized by arriving atomic oxygen. Microscopic debris on the back surface of the solar cell produced shadows of the contaminant deposited indicating that a major transport mechanism is through line of sight vapor phase transport. An image of the support mesh which was sutured around each solar cell perimeter can also be seen. The contaminant is thinner in these regions where the mesh prevented atomic oxygen from converting the silicone to silica thus allowing some amount of revolatilization of the depositing silicone prior to its conversion to silica. For this particular solar cell, the silica contaminant was measured by profilimetry to be $1.24 \mu \mathrm{m}$ thick in the areas which were not shielded from atomic oxygen by the mesh and $1.06 \mu \mathrm{m}$ where the mesh obstructed arriving atomic oxygen from converting the silicone to silica. These measurements were made in the area of the tape peeling. Measurements. by the same method. of the contaminant thickness which occurred similarly on the front surface of the solar cell were found to be up to $4.6 \mu \mathrm{m}$ thick although the contaminant was found to be comprised mostly of oxidized silicone. Small quantities of copper, iron and strontium were detected by Sparks spectroscopy analysis of the contaminant removed from the solar cell surface. With such thick contaminant layers on the surface of the solar cells, one would also expect some reduction in the transmitted solar light radiation with its attendant reduction in photovoltaic array output power. The thickly contaminated surfaces of the solar cells were much rougher than their underlying cover glass thus resulting in a much more diffusely reflecting surface which appeared as a matte white surface when viewed at grazing incidence.

High rates of organic and silicone contamination arriving at a surface with simultaneous atomic oxygen exposure can cause significant reductions in optical transmittance. Such was the case for the sun sensors on an Israeli Offeq-3 spacecraft (ref. 6). In this example, atomic oxygen interacted with silicone and hydrocarbon contamination. The interior of the spacecraft vented to the outside of the spacecraft by allowing contamination to arrive at the surfaces of the sun sensors which simultaneously were being hombarded by atomic oxygen. An additional source of silicone contamination existed early in the mission from silicone-based thermal control coatings on solar arrays prior to their full deployment. As a consequence of combined hydrocarbon, silicones and atomic oxygen interaction, a 40 to 60 percent attenuation in solar radiation being received by the sun sensors occurred resulting in the same reduction in sun sensor output in less than 150 days in LEO. A ground-laboratory experiment is currently being constructed to simulate the synergistic effects of atomic oxygen bombardment on surfaces which simultaneously are receiving contaminant fluxes of silicones as well as hydrocarbons. This experiment will be conducted with separate control of the fluxes of hydrocarbon and silicone contaminants arriving on optical surfaces by means of temperature control of sources of such contaminants. 
A silicone contamination camera is being constructed as a Get Away Special (GAS) Can experiment which uses atomic oxygen to convert silicone contaminants to silica. The purpose of the experiment is to demonstrate the ability to identify the sources of silicone contamination. To achieve this, sources of silicone are located in view of a pinhole camera which allows the contaminant to arrive on an iridium-coated fused silica substrate which is simultaneously exposed to LEO atomic oxygen. As the silicones become fixed to the iridium-coated substrate by atomic oxygen conversion of silicone to silica, there is a gradual build up of the silica in an image of the source of silicone contamination. After retrieval from space, the contaminated substrate will then be analyzed by using scanning variable angle spectroscopic ellipsometry to measure the spatial variation in contaminant thickness, thus allowing an image of the source of contamination to be produced. Such ellipsometry techniques are sensitive to monolayer levels of contamination. This technique should provide sufficient spatial resolution to produce images of the source of contamination which can occur on spacecraft or in the Shuttle bay. Figure 9 shows a drawing of the silicone contamination camera planned for use in the PEACE GAS Can experiment.

\subsection{SUMMARY}

Atomic oxygen in LEO interacts with silicone, oxidizing the methyl groups and gradually converting the silicone to silica. As a consequence of this process, a tensile stress develops in the surface of the silicone with an increase in the elastic modulus of the silicone surface. Thus, the surface of the silicone becomes hard, embrittled and cracked and has a chemistry approaching that of fused silica. If sufficiently high fluences of atomic oxygen exposure occur, then deep cracks and branch cracks can gradually develop exposing more underlying material.

Silicone contamination arriving on surfaces which are immune to oxidation from atomic oxygen attack or high flux of silicone arriving on oxidizable polymers tends to build an oxidized silicone or silica deposit with time. This is a direct result of the LEO atomic oxygen oxidation of the contaminant. Such deposits can darken in UV radiation and can be of substantial thickness for long duration missions causing changes in optical properties such as increased diffuse reflectance, decreased transmittance and increased absorptance. Gradual deposition and LEO atomic oxygen oxidation of silicone contaminants can produce a silica deposit that is low stress and crack-free unlike the results of atomic oxygen interaction with bulk silicone.

A silicone contamination pin-hole camera is being developed as part of the PEACE GAS Can experiment to evaluate the feasibility of identifying, by imaging, sources of silicone contamination in space.

\section{REFERENCES}

1. Banks, B.A., Rutledge, S.K., de Groh, K., Mirtich, M.J., Gebauer, L., Olle, R., and Hill, C.: “The Implications of the LDEF Results on Space Station Freedom Power System Materials," Proceedings of the 5th International Symposium on Materials in a Space Environment, Cannes-Mandelieu, France, Sept. 16-20, 1991.

2. Banks, B.A.: "The Use of Fluoropolymers in Space Applications," in Modern Fluoropolymers, edited by John Scheirs, John Wiley \& Sons, 1997.

3. Koontz, S.A., Leger, L., Rikman, S., Hakes, C., Bui, D., Hunton, D., and Cross, J.: "Evaluation of Oxygen Interactions with Materials III - Mission and Induced Environments," presented at the 3rd Post-Retrieval Long Duration Exposure Facility (LDEF) Symposium, Williamsburg, VA, Nov. 11, 1993.

4. Visentine, J., Kinard, W., Pinkerton, R., Brinker, D., Scheiman, D., Banks, B., Zweiner, J., Albyn, K., Farrell, T., Hornung, S., and See, T.: "Mir Solar Array Return Experiment," AlAA-99-0100, presented at the 37th AIAA Aerospace Sciences Meeting and Exhibit, Reno, NV, January 11-14, 1999.

5. Wilson, A.: Janes Space Directory, 12th edition, 1996-1997, Biddles Limited.

6. Noter, Y., Grossman, E., Genkin, L., Haruvy, Y., Murat, M., Ross, I., Vered, R., and Lifshitz, Y., Efraty, Y., Granot, H., Halbersberg, A., Luria, H., and Stoler, A.: "Variations in the Telemetry of an Offeq Satellite's Sun Sensors," presented at the 3rd International Space Forum on Protection of Materials and Structures from Low Earth Orbit Space Environment, University of Toronto Institute for Aerospace Studies, Toronto, Canada, April 25-26, 1996.

7. de Groh. K., McCollum. T.: "Low Earth Orbital Durability of Protected Silicones for Refractive Photovoltaic Concentrator Arrays," J. Spacecraft \& Rockets, 32:1, Jan.-Feb., 1995. 
8. Banks, B.A., de Groh, K., Rutledge, S., and Difilippo, F.: "Prediction of In-space Durability of Protected Polymers Based on Ground Laboratory Thermal Energy Atomic Oxygen," NASA TM-107209, presented at the 3rd International Conference for Protection of Materials and Structures from Low Earth Orbit Space Environment, University of Toronto Institute for Aerospace Studies, Toronto, Canada, April 25-26, 1996.

9. Hung, C. and Cantrell, G.: "Reaction and Protection of Electrical Wire Insulators in Atomic Oxygen Environments," NASA TM-106767, presented at the AE-8D Wire and Cable Sub-committee Meeting, Sponsored by the Society of Automotive Engineers, Albuquerque, NM, April 12-14, 1994.

10. de Groh, K., and McCue, T.: "Analysis of Contaminated Solar Array Samples Retrieved from Mir," prepared for the 34th Intersociety Energy Conversion Engineering Conference, Vancouver, B.C., Canada, Aug. 1-5, 1999.

11. Mir Solar Array Returned Experiment (SARE) Archive System. NASA Langley Research Center, Hampton, VA., http://setas-www.larc.nasa.gov/sare/sare.html, provided by the U.S. and Russian SARE Analysis Team participants.

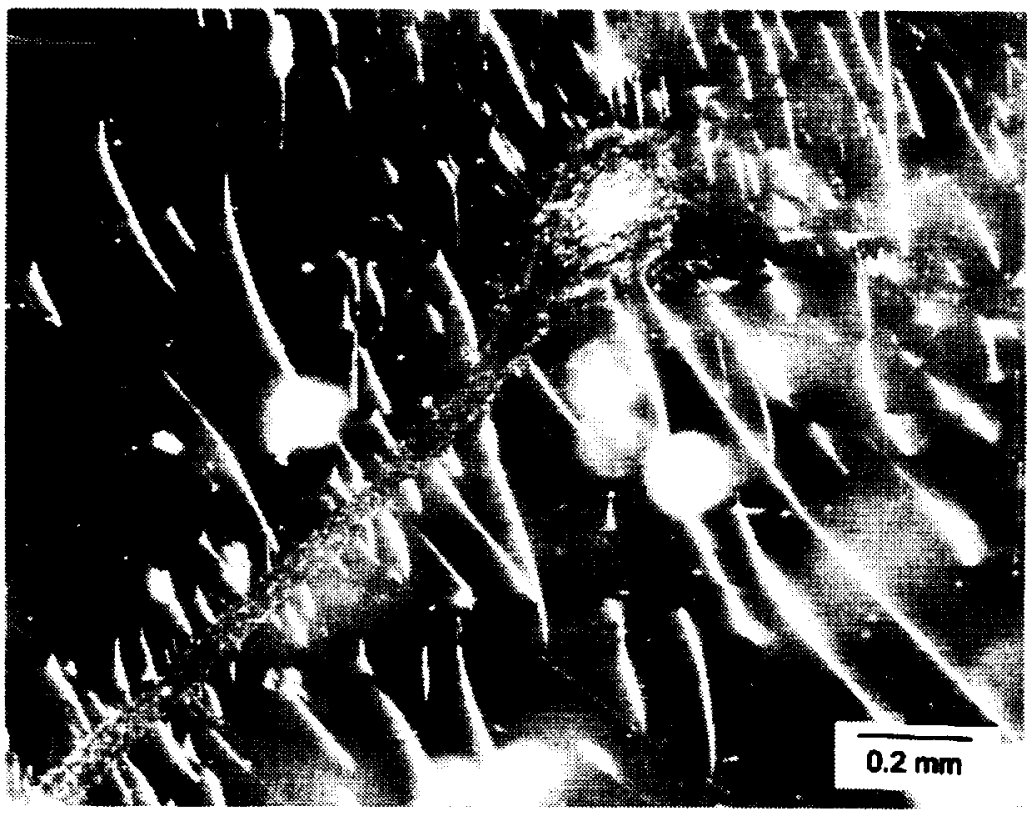

Figure 1.-DC-93-500 silicone after exposure in LEO on EOIM-III to an atomic oxygen fluence of $2.3 \times 10^{20}$ atoms $/ \mathrm{cm}^{2}$. 


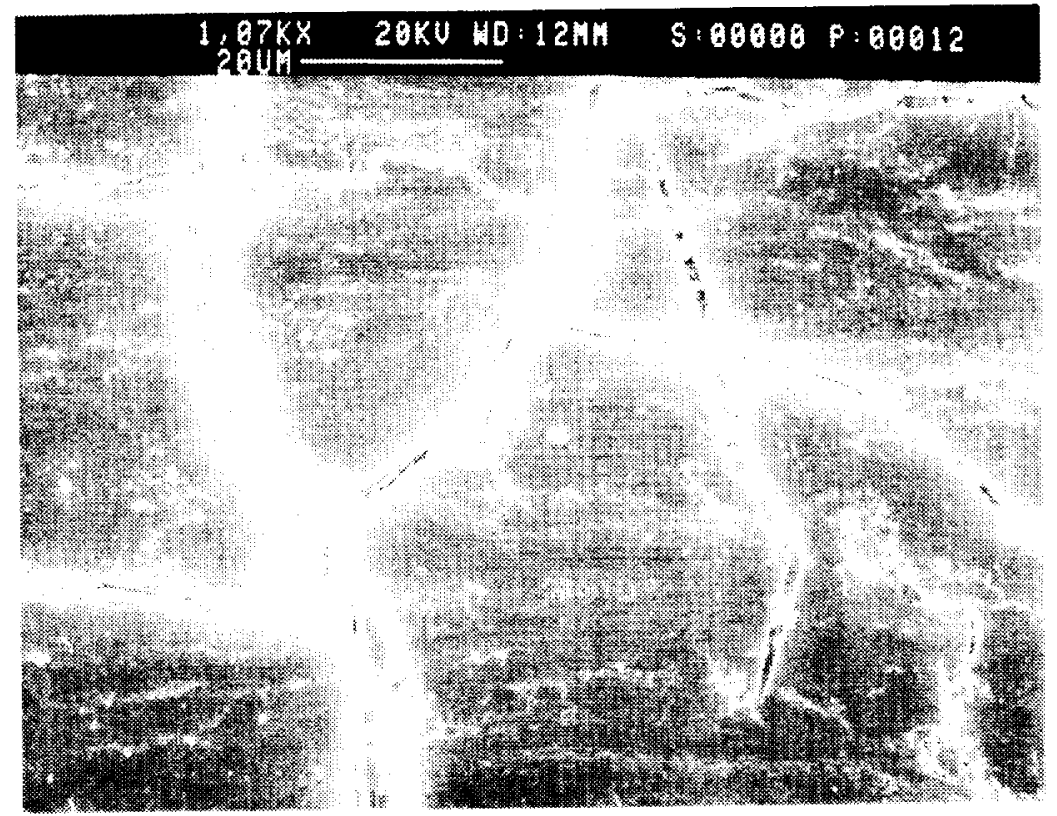

Figure 2.-Silicone adhesive associated with polyimide Kapton tape after exposure on LDEF to an atomic oxygen fluence of $4.92 \times 10^{21}$ atoms $/ \mathrm{cm}^{2}$.

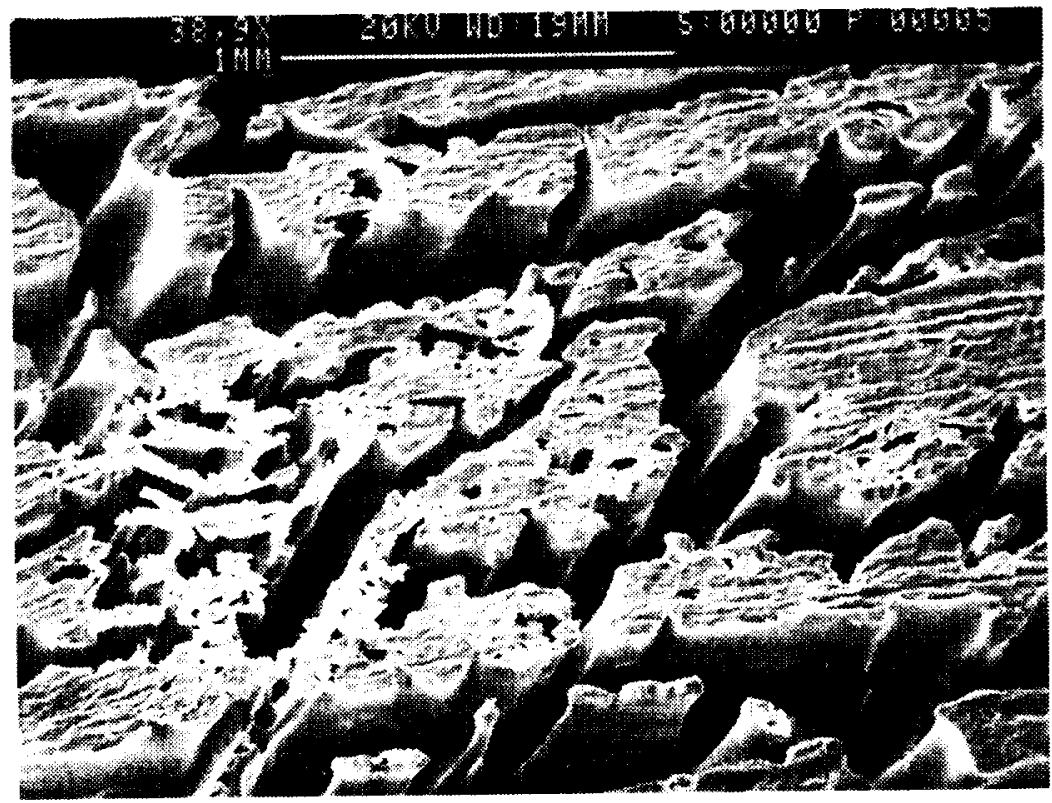

Figure 3.-Scanning electron microscope photograph of the silicone coated acrylic LDEF bicycle retroreflector after exposure to high fluence atomic oxygen. 


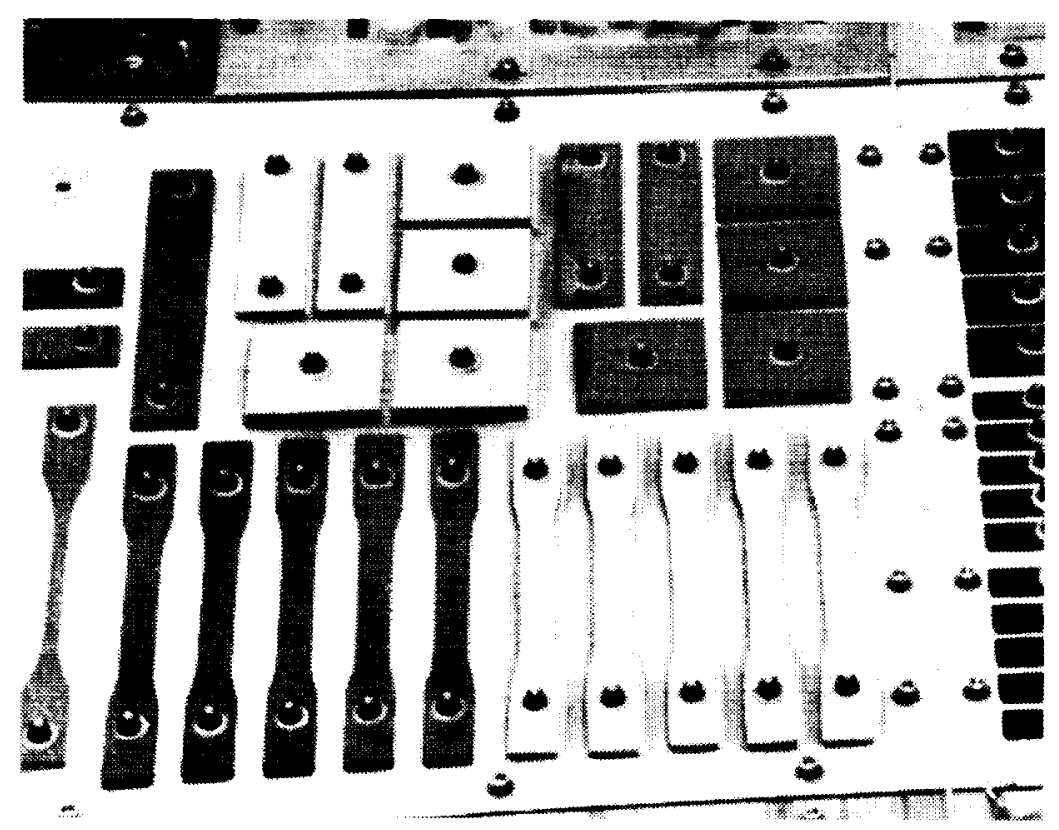

Figure 4.-Photograph of silicone contamination to the right of sample, but separated from the silicone samples by a lighter colored region which had been shielded from atomic oxygen attack approaching from the upper left.

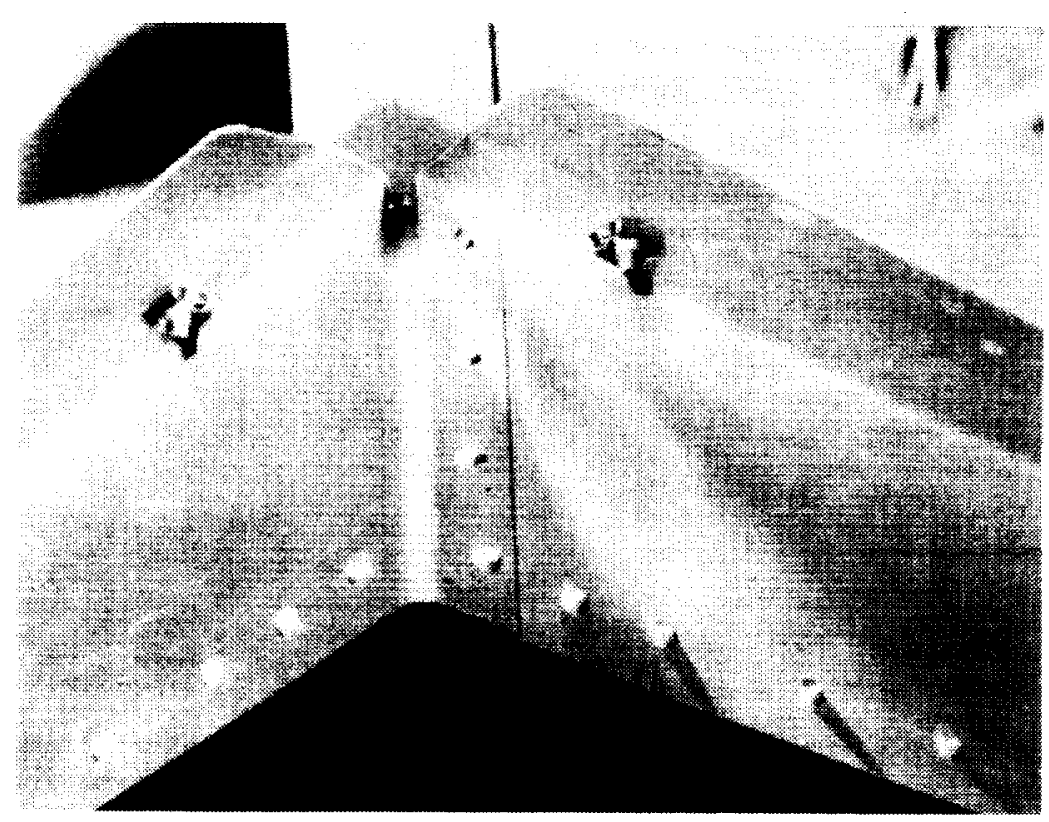

Figure 5.-LDEF experiment tray showing the effects of atomic oxygen entry from the upper left impinging upon the side of the experiment tray where simultaneous silicone contamination was being deposited and being converted to silica. 


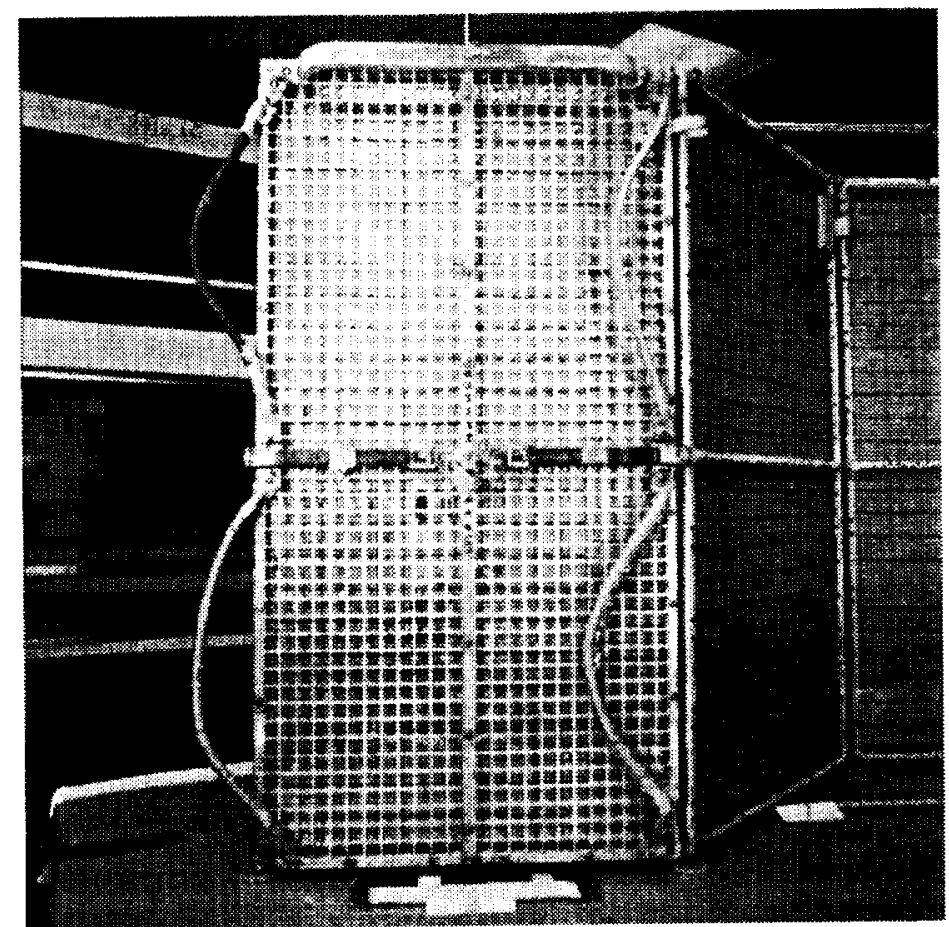

Figure 6.-Back surface of Panel 8 of a retrieved Mir solar array panel.

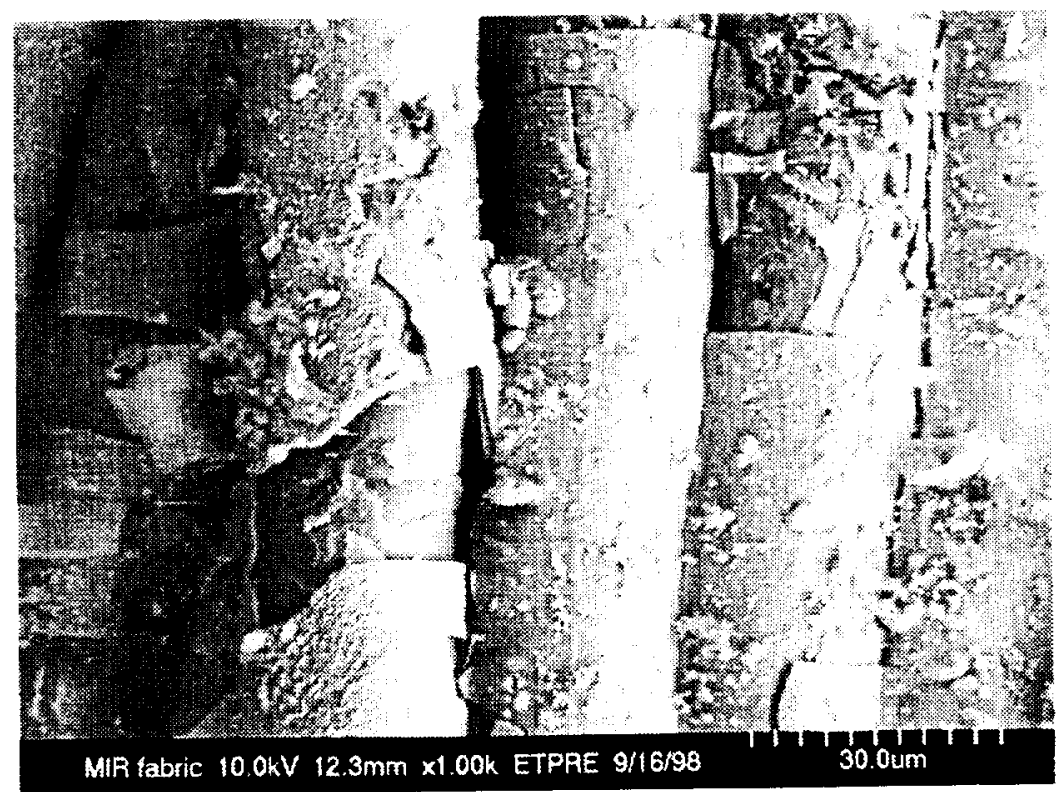

Figure 7.-Scanning electron microscope photograph of oxidized silicone contaminant on fibers of the handrails on the Mir solar array. 


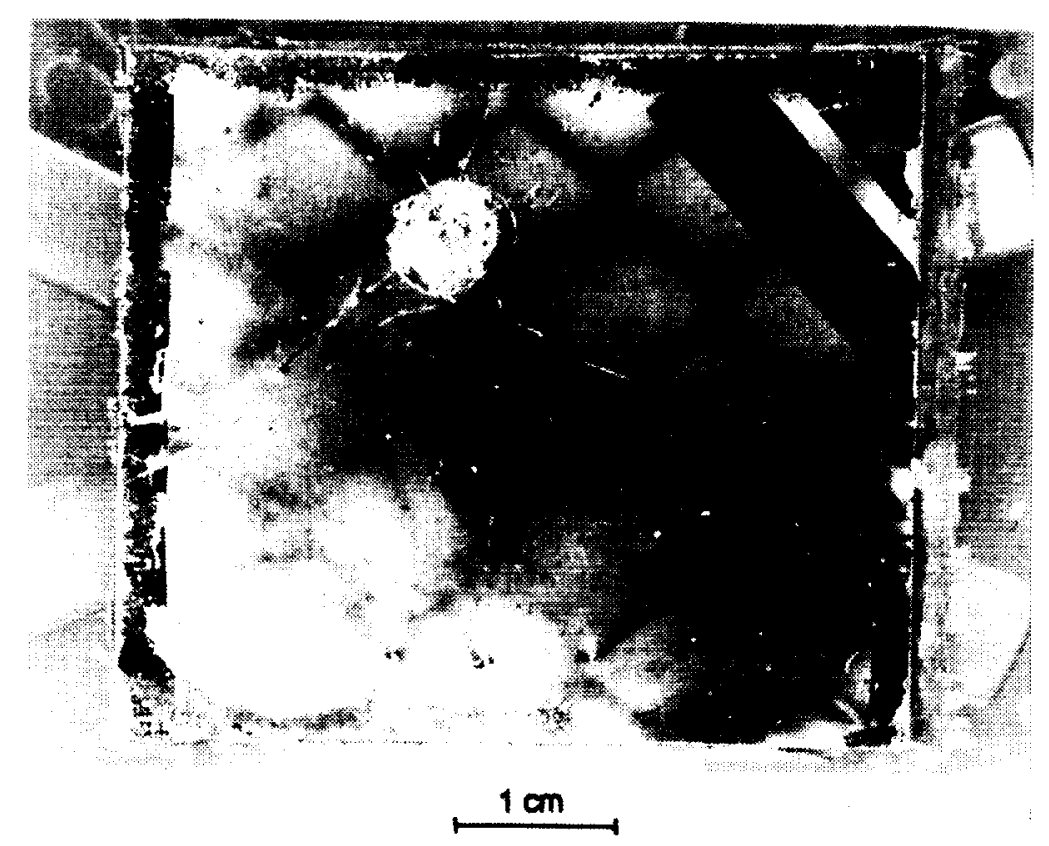

Figure 8.-Back surface of Mir solar cell $(6,16)$ showing impact site on optical solar reflector and two areas in the upper right which were cleaned of contaminant by tape peeling.

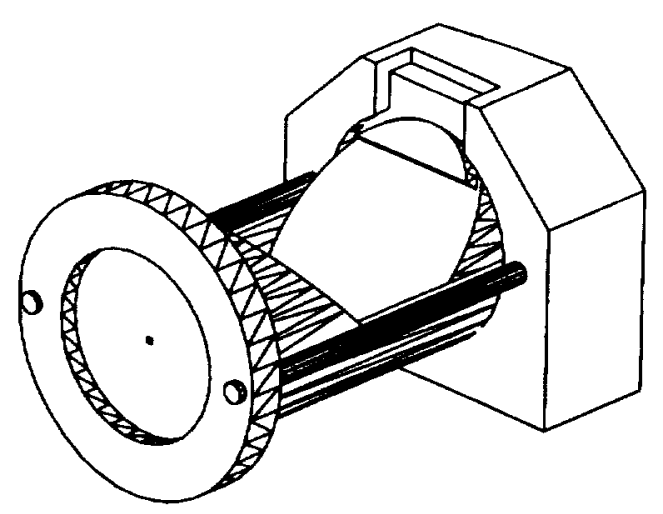

(a) Perspective assembled view

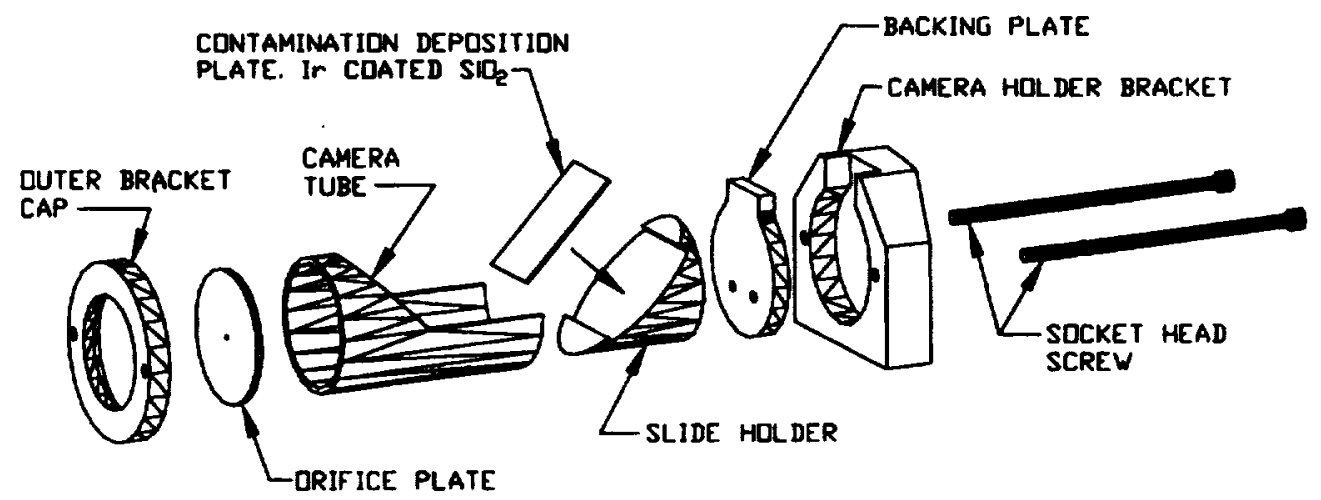

(b) Exploded view

Figure 9.-Silicone contamination camera for identification of sources of silicone contamination. 


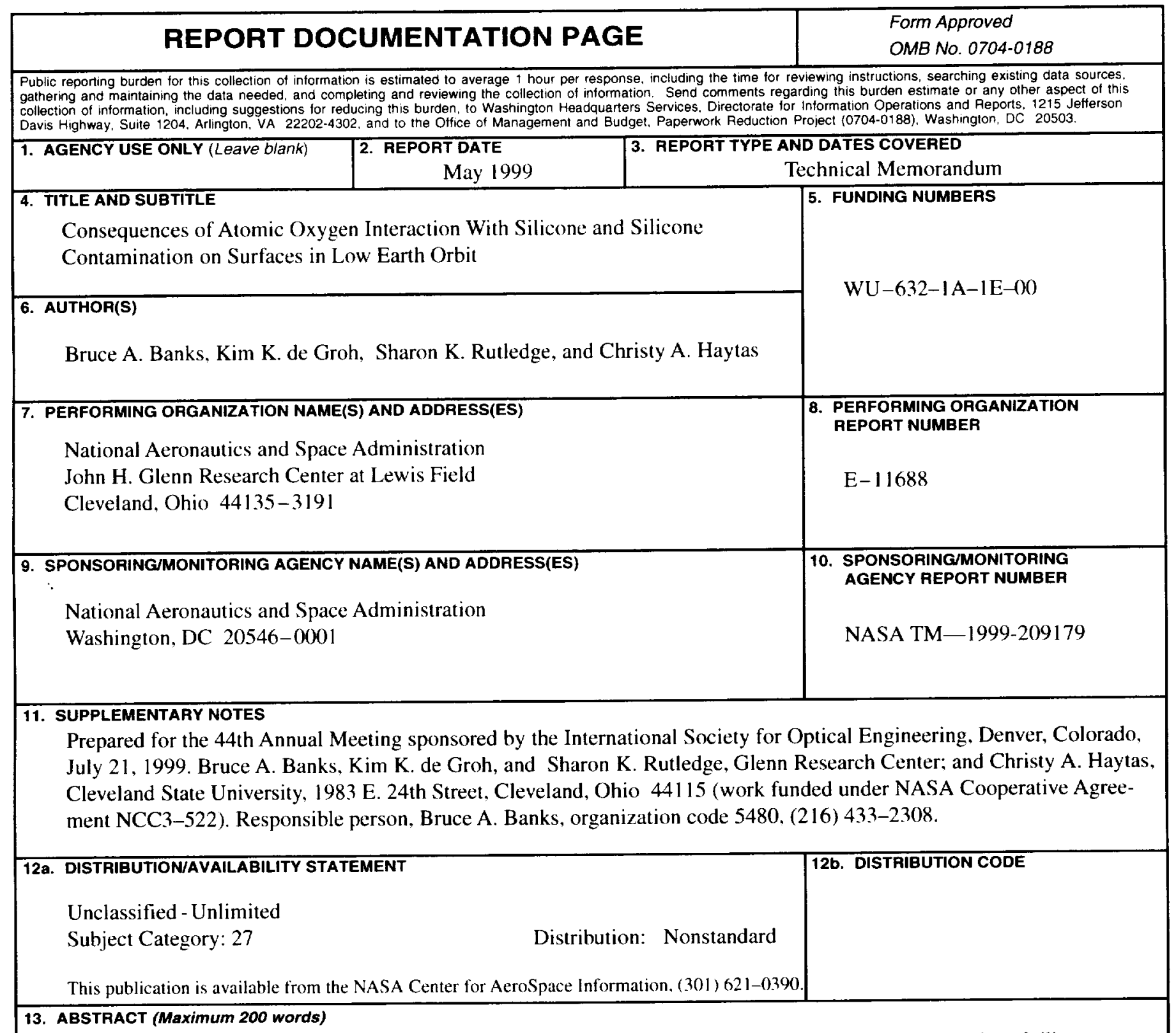

The exposure of silicones to atomic oxygen in low Earth orbit causes oxidation of the surface, resulting in conversion of silicone to silica. This chemical conversion increases the elastic modulus of the surface and initiates the development of a tensile strain. Ultimately, with sufficient exposure, tensile strain leads to cracking of the surface enabling the underlying unexposed silicone to be converted to silica resulting in additional depth and extent of cracking. The use of silicone coatings for the protection of materials from atomic oxygen attack is limited because of the eventual exposure of underlying unprotected polymeric material due to deep tensile stress cracking of the oxidized silicone. The use of moderate to high volatility silicones in low Earth orbit has resulted in a silicone contamination arrival at surfaces which are simultaneously being bombarded with atomic oxygen. thus leading to conversion of the silicone contaminant to silica. As a result of these processes, a gradual accumulation of contamination occurs leading to deposits which at times have been up to several microns thick (as in the case of a Mir solar array after 10 years in space). The contamination species typically consist of silicon, oxygen and carbon, which in the synergistic environment of atomic oxygen and UV radiation leads to increased solar absorptance and reduced solar transmittance. A comparison of the results of atomic oxygen interaction with silicones and silicone contamination will be presented based on the LDEF. EOIM-III. Offeq-3 spacecraft and Mir solar array in-space results. The design of a contamination pin-hole camera space experiment which uses atomic oxygen to produce an image of the sources of silicone contamination will also be presented.

\section{SUBJECT TERMS}

Atomic oxygen; Protective coatings; Silicone contamination; Pin-hole camera

\begin{tabular}{|c|c|c|}
\hline $\begin{array}{c}\text { 17. SECURITY CLASSIFICATION } \\
\text { OF REPORT } \\
\text { Unclassified }\end{array}$ & $\begin{array}{c}\text { 18. SECURITY CLASSIFICATION } \\
\text { OF THIS PAGE } \\
\text { Unclassified }\end{array}$ & $\begin{array}{c}\text { 19. SECURITY CLASSIFICATION } \\
\text { OF ABSTRACT } \\
\text { Unclassified }\end{array}$ \\
\hline
\end{tabular}


